\author{
В. Г. Цірук, к.т.н., головний інженер \\ ПАТ «НВО «Київський завод автоматики» \\ Старокиївська, 10, м. Київ, 04116, Україна
}

\title{
ВИЗНАЧЕННЯ ПАРАМЕТРІВ МЕТАЛЕВОГО РЕЗОНАТОРА ВІБРАЦІЙНОГО ГІРОСКОПА АКУСТИЧНИМ МЕТОДОМ
}

\begin{abstract}
У роботі наведено результати розробки та визначення параметрів високотехнологічного, дешевого коріолісового вібраиійного гіроскопа, який забезпечує високу точність вимірювань та не поступається своӥми характеристиками його основним конкурентам: волоконнооптичному і лазерному гіроскопу. Показано, шо для збільшення технологічності $i$ зменшення вартості виготовлення резонатора його слід виготовляти з металу. Запропоновано акустичний метод, ще дає змогу визначати добротність різних типів коливань для довільної кількості неоднорідностей залежно від місия їх розтамування в резонаторі, а також параметри добротності самого резонатора. Оцінено правильність проведення операцій термообробки та неоднорідність розподілу маси по окружній координаті резонатора, а також можливість використання резонаторів на подальших етапах складання.
\end{abstract}

Ключові слова: коріолісовий гіроскоп, навігаџія, балансування, акустика.

Актуальність теми дослідження. Останнім часом досягнуто високий рівень нових розробок чутливих елементів систем стабілізації та орієнтації. Однією з таких розробок $є$ коріолісовий вібраційний гіроскоп $($ КВГ), робота якого базується на інерційних властивостях пружних хвиль, що збуджуються в резонаторах на звукових частотах. Саме коріолісовий вібраційний гіроскоп являє собою важливу складову для створення інерціальної технології не тільки тому, що ці гіроскопи продемонстрували високу якість, як, наприклад, кварцовий напівсферичний резонаторний гіроскоп, а й тому, що два інші найбільш популярні типи твердотільних гіроскопів (кільцевий лазерний та волоконнооптичний) поки не піддаються тому рівню мініатюризації, як коріолісовий вібраційний гіроскоп.

Тому, актуальним і перспективним $\epsilon$ створення високотехнологічного, дешевого КВГ, що забезпечує високу точність вимірювань і не поступається метрологічними характеристиками його основним конкурентам: волоконно-оптичному і лазерному гіроскопам

Постановка проблеми. В статті проводиться аналіз конструкції чутливого елемента коріолісового вібраційного гіроскопа, а також розглядаються створені за участю автора алгоритми управління пружною хвилею резонатора такого гіроскопа та вимірювання ії частоти. 3 метою забезпечення високої точності гіроскопа конструкція резонатора має забезпечувати ідентичність двох мод коливань (первинної і вторинної), тому що в цьому випадку отримується максимальна точність приладу. Крім того, конструкція повинна мати строгу осьову симетрію. Відомі дві геометричні фігури, що мають високу осьову симетрію: сфера і циліндр. Останній буде розглядатися як модель металевого резонатора вібраційного гіроскопа при визначенні його параметрів акустичним методом.

Аналіз останніх досліджень та публікацій. Досягнення високої точності комплексів стабілізації стало можливим завдяки високій якості сучасних елементів гіроскопічної техніки і значному розвитку теорії гіроскопічних пристроїв працями відомих вченихматематиків і механіків, серед яких можна відзначити монографію [1].

При цьому, у наукових працях вчених В. В. Карачуна, В. П. Кваснікова, В. М. Мельника, Х. Міягави, С. Тадано, Р. Такедо та інших показано провідну роль досягнень у розробці інерціальних систем навігації та їх чутливих елементів [2-5].

У той же час питання метрології, дослідження похибок чутливих елементів комплексів стабілізації були висвітлені у роботах О. М. Безвесільної, М. Д. Кошового, О. І. Осмоловського тощо [6-8].

Проте досі залишається невизначеним питання розрахунку добротності КВГ акустичним методом, що дозволило б забезпечити 
високу точність вимірювання його коливних характеристик.

Мета роботи: визначити і математично описати методику акустичної перевірки та розрахунку добротності резонатора для подальшого коригування його маси та забезпечення точності вимірювання коливання хвилі.

Виклад основного матеріалу. Типову конструкцію резонатора коріолісового вібраційного гіроскопа зображено на рис. 1.

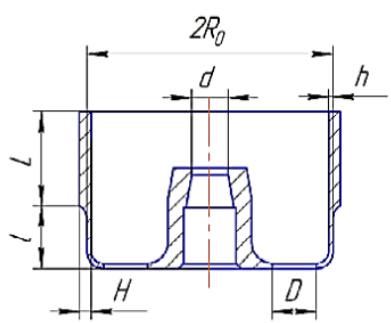

a)

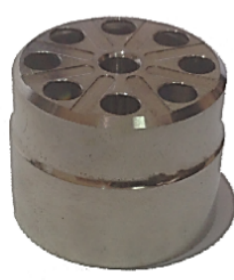

б)
Рис. 1. Схема циліндричного резонатора 3 циліндричним вузлом кріплення $(a)$ та його загальний вигляд (б)

Оскільки товщина циліндричної частини пружного підвісу менша товщини обода $h<H$, то його власна частота зміщена в нижній діапазон частот.

Це видно з виразу для резонансної частоти циліндричної оболонки:

$$
\omega_{i}=K(i) \frac{h}{R_{0}^{2}} \sqrt{\frac{E}{(1+v) \rho}},
$$

де $K(i)=\frac{i\left(i^{2}-1\right)}{\sqrt{\left(i^{2}+1\right)}}-$ коефіцієнт, залежний

від номера $i$ моди коливань, $E$ - модуль Юнга, $v$ - коефіцієнт Пуассона, $\rho$ - щільність матеріалу.

В результаті цього досягається частотна розв'язка між робочою частотою коливань (резонансною частотою обода) i частотою підвісу (у нижній частині циліндра), на якій розташований обід.

Тому пружний підвіс у такій конструкції виконує роль демпфера при дії зовнішніх збурень - вібрацій і ударів.

Зменшення товщини пружного підвісу призводить до зменшення його моменту інерції $\mathrm{i}$, тим самим, знижує вимоги до точності виготовлення і до рівності пружних властивостей спиць.
Це видно із співвідношення моментів інерції кільцевого обода $M_{\kappa}$ і підвісу $M_{n d}$, приведених до амплітуди коливань резонатора:

$$
\frac{M_{n d}}{M_{k}}=\left(\frac{h}{H}\right)^{2} .
$$

Тому при виконанні співвідношення $h / H \leq 1 / 4$ вимоги до точності виконання пружного підвісу зменшуються (ослаблюються) більше, ніж на порядок.

Високі вимоги до точності геометричної форми і пружних властивостей накладаються тільки на обід резонатора, що значно підвищує технологічність $i$, отже, знижує вартість його виготовлення [9].

Дно резонатора і менша по товщині нижня частина циліндра виконують роль пружного підвісу, але, оскільки на дні розташовуються датчики знімання і збудження, які збільшують жорсткість по осях їх розташування, то для забезпечення коливань резонатора по цих осях необхідно збільшити жорсткість частини дна між датчиками.

Проте між датчиками розташовані отвори, тому порівняємо жорсткості уздовж осі спиці і осі, що проходить через центр отвору.

Жорсткість спиць, які утворюються між отворами, визначається як

$$
C_{c n}=\frac{E h^{3}}{12 R_{0}^{2}} .
$$

Жорсткість дна уздовж осі, що проходить через центри отворів діаметром $D$ (рис. 1), для круглих отворів визначається як

$$
C_{z}=\frac{E h^{3}}{12\left(R_{0}-D\right)^{2}} .
$$

Для того щоб максимальні коливання збуджувалися уздовж осей, необхідно виконати умову

$$
C_{c n} / C_{z}<1 .
$$

Жорсткість датчиків визначається як:

$$
C_{\partial}=\frac{E_{\partial} b h_{\partial}^{3}}{12 a^{3}},
$$

де $E_{\partial}$ - модуль Юнга, $b, a, h_{\partial}$ - ширина, довжина і товщина датчиків.

Сумарна жорсткість спиці і розташованих на ній датчиків при співвідношенні розмірів $a=R_{0} / 2, h_{\partial}=h$ дорівнює 


$$
C_{\Sigma}=\frac{E h^{3}}{12 R_{0}^{2}}\left(1+\frac{8 E_{\partial} b}{E R_{0}}\right) .
$$

Для виконання умови (5) вимагається, щоб

$$
\left(1-\frac{d}{R_{0}}\right)^{2}\left(1+\frac{8 E_{\partial} b}{E R_{0}}\right)<1 .
$$

Умова (8) виконується при $D \geq R_{0} / 2$.

Таким чином, якщо діаметр отвору буде більшим половини радіуса циліндра, то деформація дна циліндра зосередиться на спицях $і$ буде виміряна датчиками.

На рис. 2 показано стоячу хвилю у циліндричному резонаторі.

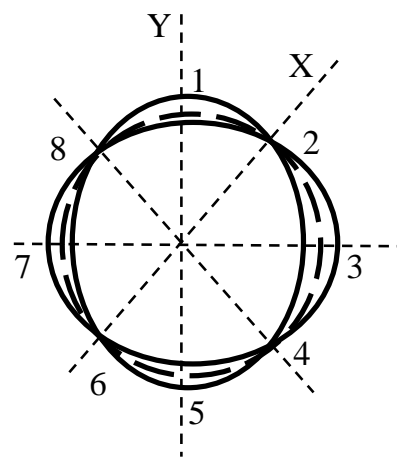

Рис. 2. Стояча хвиля У циліндричному резонаторі

Після виготовлення резонаторів необхідно перевірити точність їх виготовлення.

Першочергово перевіряються його геометричні параметри. Їх перевірка відбувається на спеціальному обладнанні.

Задля отримання високих параметрів точності та чутливості гіроскопічного датчика необхідно, щоб резонатор був виконаний із максимальною точністю (3 мінімальними відхиленнями від круглості та симетричності відносно осі деталі).

Геометричні параметри резонатора задаються з точністю до 0,001 мм.

Таким чином, необхідний $100 \%$ контроль резонаторів на відповідність вимогам креслення.

Контроль таких параметрів дозволяє виконати кругломір. Результати замірів наносяться на кругову діаграму (рис. 3).

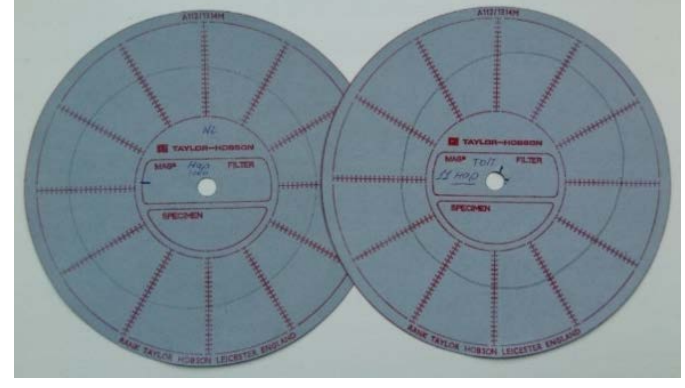

Рис. 3. Діаграма результатів вимірювання

Основна особливість різниці у вимірюваннях полягає в наступному: якщо вважати, що профіль деталі $\mathrm{\epsilon}$ періодичною кривою синусоїдальної форми, причому на окружності укладається $n$ періодів відхилень, то показання приладу будуть пов’язані зі значенням відхилення від круглості рівнянням

$$
X(p)=\int_{-\infty}^{\infty} x(D) e^{-p D} d t=L\{x(D)\},
$$

де $D$ - вимірювальний діаметр, $p$ - відносна похибка.

Другим етапом перевірки виконання операцій термообробки $є$ перевірка параметрів резонатора акустичним методом.

Основними параметрами при перевірці $€:$

- резонансні частоти;

- різночастотність;

- добротність.

Для перевірки цих параметрів спроектовано спеціальне робоче місце (рис. 4), що дозволяє здійснювати обробку акустичних даних за допомогою ЕОМ.

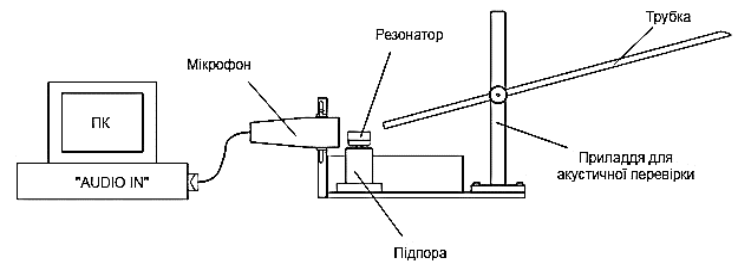

Рис. 4. Схема робочого місця по перевірці акустичних параметрів металевого резонатора

Метод полягає в аналізі звукових коливань в резонаторі після дії механічних збурень.

Ці збурення виникають внаслідок контакту металевої кульки, що скочується по трубці приладдя, з робочою поверхнею резонатора. 
Звукові сигнали, що виникають в результаті зіткнення, записуються мікрофоном та оброблюються у цифровому вигляді за допомогою ЕОМ.

Типову діаграму обробленого сигналу зображено на рис. 5.

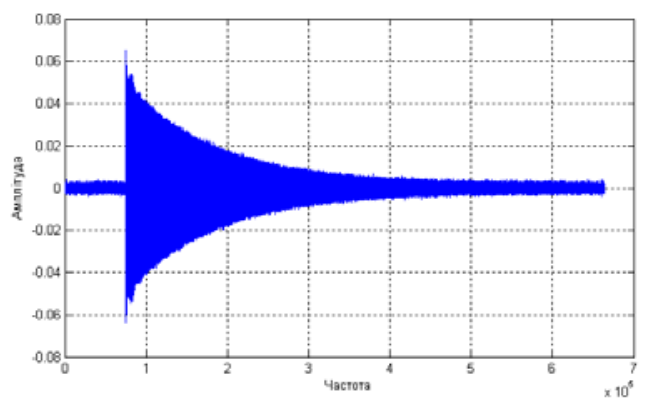

Рис. 5. Діаграма обробленого звукового сигналу при збудженні

Використовуючи швидке перетворення Фур'є для проведення спектрального аналізу, визначаємо робочі резонансні частоти резонатора (рис. 6).



Рис. 6. Резонансні частоти резонатора у збудженому стані

Різночастотність визначається за формулою

$$
\Delta F=F_{p 2}-F_{p 1},
$$

де $F_{p 1}$ та $F_{p 2}-$ значення першого та другого резонансних піків.

Аналіз цих даних дозволяє оцінити можливості подальшого використання резонаторів, адже для витримки ізотропності амплітуди коливань резонатора його необхідно відбалансувати.

Вимогою до параметра різночастотності $€: \Delta F \leq 10$ Гц.

Добротність - параметр коливальної системи, що визначає ширину резонансу та характеризує, у скільки разів запаси енергії в системі більші, ніж втрати енергії за один період коливань.
Добротність зворотно пропорційна швидкості затухання власних коливань у системі. Тобто, чим вища добротність коливальної системи, тим менші втрати енергії, тим повільніше затухають коливання.

В металевих резонаторах втрата енергії відбувається на стінках резонатора, його матеріалі та в елементах зв'язку.

Добротність резонаторів визначається за формулою

$$
Q=\frac{F_{p}}{F_{2}-F_{1}},
$$

де $F_{p}$ - резонансна частота; $F_{1}, F_{2}$ - частоти на рівні 0,707 амплітуди вихідного сигнала резонансної частоти (рис. 7).

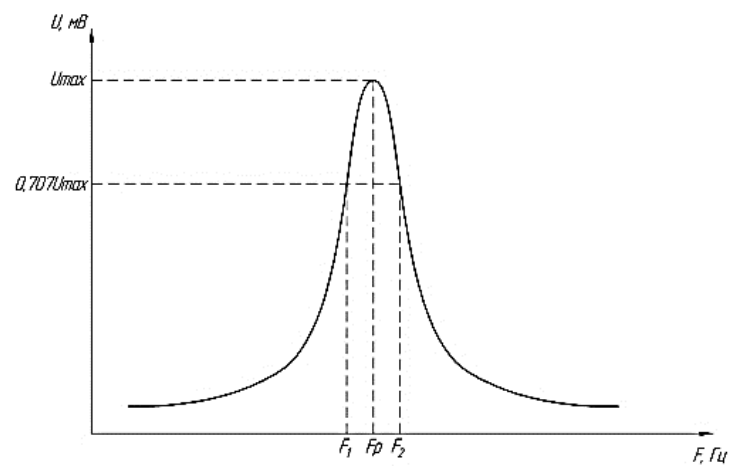

Рис.7. Типовий резонансний пік у металевому резонаторі при збудженні

Висновки. Визначено та математично описано методику акустичної перевірки та розрахунку добротності коріолісового вібраційного гіроскопа.

Доведено, що використання швидкого перетворення Фур'є для проведення спектрального аналізу дозволяе визначити робочі резонансні частоти резонатора КВГ.

Встановлено, що визначення параметра добротності дає змогу оцінити правильність проведення операцій термообробки, а також неоднорідність розподілу маси по окружній координаті резонатора при використанні резонаторів на етапах складання.

\section{Список літератури}

1. Павлов В. О. Гироскопический эффект, его проявления и использование. Ленинград: Судостроение, 1985. 256 с.

2. Karachun V. V., Mel'nik V. N. Determining gyroscopic integrator errors due to diffraction of sound waves. International Applied Mechanics. 2004. № 3. C. 328-336. 
3. Tadano S., Takeda R., Miyagawa H. Threedimensional gait analysis using wearable acceleration and gyro sensors based on quaternion calculations. Sensors. 2013. Vol. 13, № 7. P. 9321-9343. doi: 10.3390/s130709321

4. Xia D., Yu C., Kong L. The development of micromachined gyroscope structure and circuitry technology. Sensors. 2014. Vol. 14, № 1. P. 1394-1473. doi: 10.3390/s140101394

5. Квасніков В. П., Кочеткова О.В.Проектування вимірювальної системи на нейронних мережах. Автоматика. Автоматизація. електротехнічні комплекси і системи. 2005. № 2. С. 138-141.

6. Квасніков В. П., Осмоловський О. І. Підвищення динамічної точності слідкуючих систем 3 обмеженою лінійною зоною датчика відхилення. Електроніка та системи управління. 2005. № 2. С. 128-131.

7. Безвесільна О. М., Кошовий М. Д. Вимірювання лінійних прискорень на основі штучної нейтронної мережі. Вісник Iнженерної академії України. 2012. № 3. C. 80-84.

8. Безвесільна О. М., Ц Цірук В. Г., Квасніков В. П. Аналіз закордонних систем наведення та стабілізації. Вісник Інженерної академії України. 2014. № 2. С. 155159.

9. Антонюк В. С., Возняковський А. О., Пономаренко А. І., Цірук В. Г. Спосіб виготовлення резонатора коріолісового вібраційного гіроскопа: пат. № 125819 Україна. МПК 7G01C 19/00; опубл. 25.05.2018, бюл. № 10/2018.

\section{References}

1. Pavlov, V. O. (1985) Gyroscopic effect, its manifestation and use. Leningrad: Sudostroeniye, 256 p. [in Russian].
2. Karachun, V. V., Mel'nik, V. N. (2004) Determining gyroscopic integrator errors due to diffraction of sound waves. International Applied Mechanics, No. 3, pp. 328-336.

3. Tadano, S., Takeda, R., Miyagawa, H. (2013) Three-dimensional gait analysis using wearable acceleration and gyro sensors based on quaternion calculations. Sensors, Vol. 13, № 7, pp. 9321-9343. doi:10.3390/s130709321

4. Xia, D., Yu, C., Kong, L. (2014) The development of micromachined gyroscope structure and circuitry technology. Sensors, Vol. 14, № 1, pp. 1394-1473. doi: 10.3390/s140101394

5. Kvasnikov, V. P., Kochetkova, O. V. (2005) Development of measuring system on neural networks. Avtomatyka. Avtomatyzacija. elektrotekhnichni kompleksy i systemy, No. 2, pp. 138-141 [in Ukrainian].

6. Kvasnikov, V. P., Osmolovsjkyj, O. I. (2005) Increasing the dynamic accuracy of monitoring systems with a limited linear zone of deviation sensor. Elektronika ta systemy upravlinnja, No. 2, pp. 128-131 [in Ukrainian].

7. Bezvesiljna, O. M., Koshovyj, M. D. (2012) Measurement of linear accelerations on the basis of artificial neutron network. Visnyk Inzhenernoji akademiji Ukrajiny, No. 3, pp. 80-84 [in Ukrainian].

8. Bezvesiljna, O. M., Tsiruk, V. H., Kvasnikov, V. P. (2014) Analysis of foreign systems of guidance and stabilization. Visnyk Inzhenernoji akademiji Ukrajiny, No. 2, pp. 155159 [in Ukrainian].

9. Antonjuk, V. S., Voznjakovsjkyj, A. O., Ponomarenko, A. I., Tsiruk, V. H. A method of manufacturing a resonator of a coriolis vibration gyroscope. Patent 125819 Ukraine 7G01C 19/00). Published 25.05.2018, bull. No. $10 / 2018$.

V. H. Tsiruk, Ph.D., chief engineer

PJSC «NPO«Kiev Automation Plant»

Starokievskaya str., 10, Kyiv, 04116, Ukraine

\section{DETERMINATION OF PARAMETERS OF METALLIC RESONATOR OF VIBRATORY GYROSCOPE BY ACOUSTIC METHOD}

The results of the development and determination of parameters of high-tech, cheap coriolis vibratory gyroscope, which provides high accuracy of measurements and is not inferior to the characteristics of its main competitors: fiber-optic and laser gyroscopes, are presented in the work. It is 
shown that in order to increase the productivity and to reduce the cost of resonator manufacturing, it should be made of metal. The acoustic method is proposed, which allows to determine the Q-factor of different types of oscillations for an arbitrary number of heterogeneities, depending on their location in the resonator, as well as the parameters of the Q-factor of the resonator itself. The correctness of the heat treatment operations and the heterogeneity of mass distribution along cohesive coordinates of the resonator, as well as the possibility of using resonators at subsequent stages of assembling are evaluated.

Keywords: coriolis gyroscope, navigation, balancing, acoustics.

Стаття надійшла до редакиії 24.09.2018.

Рецензенти: В. С. Антонюк, д.т.н., професор,

В. Я. Гальченко, д.т.н., професор. 